\title{
Impact of hypoglycemia on daily life of type 2 diabetes patients in Ukraine
}

This article was published in the following Dove Press journal:

Journal of Multidisciplinary Healthcare

8 July 2013

Number of times this article has been viewed

\section{Olena Mandrik ${ }^{1-3}$ \\ Johan L Severens' \\ Olena Doroshenko ${ }^{4}$ \\ Vladymir Pan'kiv 5 \\ Nonna Kravchun ${ }^{6}$ \\ Maryna Vlasenko ${ }^{7}$ \\ Mykola Hulchiy ${ }^{8}$ \\ Maryna Baljuk ${ }^{9}$ \\ Yuliia Komisarenko ${ }^{10}$ \\ Eugene Martsynik" \\ Liubov Sokolova ${ }^{12}$ \\ Olga Zalis'ka \\ Boris Mankovsky ${ }^{13}$}

'Erasmus University Rotterdam, Rotterdam, the Netherlands; ${ }^{2}$ Danylo Halytsky Lviv National Medical University, Lviv, ${ }^{3}$ MSD Ukraine, ${ }^{4}$ Ukrainian Institute for Strategic Research, ${ }^{5}$ Ukrainian

Scientific Centre of Endocrine Surgery, ${ }^{6}$ Institute of Problems of Endocrine

Pathology na VY Danylevskogo, Ukrainian Academy of Medical Sciences, Kyiv,

${ }^{7}$ Vinnitsa National Medical University named after MI Pyrogov, Vinnytsia, Center, Kyiv, ${ }^{9}$ Danilevsky Institute of Academy of Medical Sciences, Kharkov, ${ }^{10} \mathrm{OO}$ Bogomolets National Medical University, Kyiv, "Medical Academy of Dnepropetrovsk, Dnepropetrovsk, ${ }^{12}$ Institute of Endocrinology and Metabolism after V.P. Komissarenko, National Academy of Medical Sciences of Ukraine, Kyiv, ${ }^{13} \mathrm{PL}$ Shupik National Medical Academy of Postgraduate Education, Kyiv, Ukraine

Correspondence: Olena Mandrik, Erasmus University Rotterdam, PO Box 1738, 3000 DR Rotterdam, The Netherlands

Tel +3। I0 4088525

Email olena.dem@gmail.com
${ }^{8}$ Kyiv City Teaching Endocrinological Endocrine Pathology Problems, Ukrainian

Abstract: This study evaluates the impact of hypoglycemia on the lives of Ukrainian patients with type 2 diabetes mellitus. The secondary objective was to explore patient-physician relationships and the attitudes of patients towards various informational resources on diabetes management. Three focus groups with 26 patients were conducted. Qualitative information was evaluated using content analysis. The results show that patients with type 2 diabetes mellitus in Ukraine are adapting to potential attacks of hypoglycemia; however, they still experience periodic manifestations of hypoglycemia that significantly affect their psychological well-being. This result is similar to observations made in other countries. Ukrainian patients $>40$ years old mainly receive information on disease management from endocrinologists, and rarely use internet resources on diabetes management. Information provision was especially important at the early stage of the disease, when patients lack information on hypoglycemia manifestations and could therefore fail to identify and manage it properly.

Keywords: diabetes, quality of life, developing countries, Europe, eastern

\section{Introduction}

Hypoglycemia is a common complication when treating diabetes mellitus ${ }^{1}$ and is characterized with (but not limited to) the following symptoms: sweating, palpitations, shaking, hunger, confusion and drowsiness. ${ }^{2}$ Research on the daily lives of patients with hypoglycemia concludes that the frequency of hypoglycemic episodes is correlated with lower general health, greater fear and anxiety, lower health-related quality of life (HRQoL), higher risk of long-term complications and mortality, reduced work productivity, and problems performing certain daily activities. ${ }^{1,3-10}$ Some of the major issues explored in past research include the frequency of hypoglycemic symptoms and their characteristics, ${ }^{11}$ patients' understanding of hypoglycemic symptoms and their severity, ${ }^{9,12,13}$ limitation on daily life because of hypoglycemia, ${ }^{7,8,10}$ and psychological impact of hypoglycemia..$^{9,10,14}$

Past research points to several other factors that can have an impact on how patients manage hypoglycemia caused by type 2 diabetes mellitus. For example, patients' education has a direct impact on awareness and, therefore, on the severity of hypoglycemia. ${ }^{11}$ Various informational resources can be used for patients' awareness programs. In a number of countries, information on diabetes (including hypoglycemia) management is usually provided by the primary care practitioner. ${ }^{8,15-17}$ In such cases patient-doctor relationships become very important for effective disease management. An apparent lack of concern from health care providers can have a negative impact on the emotional state of patients. ${ }^{14,18}$ 
This previous research has been conducted largely in developed countries. Unfortunately there is little to no research on this topic conducted in Ukraine or any other developing country in Eastern Europe. It is also recognized that a number of factors, such as receiving insulin therapy, obesity, diabetes complications, age, sex, employment status, educational level, level of physical activity, and ethnicity, among others, might have an impact on perceived HRQoL of type 2 diabetic patients. These factors vary from region to region and might be influenced by country-specific socioeconomic and lifestyle factors. Thus, the results from past research might not be generalizable between geographic regions.

There are no studies available for Ukraine or any other developing country of Eastern Europe that give insight on the potential impact of hypoglycemia on the daily life of patients with type 2 diabetes. However, studies on the impact of hypoglycemia on patients' lives have been undertaken in other areas worldwide, often using focus groups. ${ }^{10,12,14}$ For these reasons, this study was undertaken to evaluate the perceived burden of hypoglycemia on patients' daily life in one of the developing countries, Ukraine. The primary objective of this qualitative study was to evaluate, through focus groups with type 2 diabetes mellitus patients who had at least one reported case of hypoglycemia during the last year of treatment, the symptoms that are experienced, how they are managed, how hypoglycemia episodes can limit patients' daily life, and what is the psychological impact of hypoglycemia from the perspective of Ukrainian patients. A secondary objective was to explore patient-physician relationships and attitudes of patients towards various informational resources on diabetes management in Ukraine.

\section{Methods}

\section{Focus groups of patients with hypoglycemia}

We selected the focus groups-method to evaluate impact of hypoglycemia on patients' lives, and to assess hypoglycemia awareness and which are the most frequently used sources of information for the management of type 2 diabetes mellitus. ${ }^{10,12,14}$ General principles of the focus group method, ${ }^{19-21}$ and past focus group studies conducted on patients with type 2 diabetes mellitus ${ }^{10,12,14}$ were referred to for discussion guide design and data analysis.

A purposive sampling strategy was applied to recruit an age-homogeneous group with participants $>40$ years, and having at least one reported case of hypoglycemia during the last year of medical observation. A total of three focus groups were conducted (women $n=14$, men $n=5$ and men $n=7$ ), with patients from one of the largest cities of Ukraine and its surroundings. The sexual division aimed to stimulate more open discussion among the participants and to eliminate a sexual bias. ${ }^{12}$ The male focus group was conducted twice because of lower recruitment rate compared to women. All focus groups were organized at an independent clinical location with the aim of not influencing disclosure of information by the participants.

All participants confirmed knowledge of Russian language as fluent. If eligible, potential participants were contacted by their physician to explain the purpose of the research with an invitation, and gave a verbal agreement to participate. Institutional Review Board approval was received prior to the initiation of the study.

The majority of the participants were not acquainted with each other. Thus, an informal introduction session was organized for participants prior to the focus groups to help them to open up. Before starting the focus groups, all participants were again introduced to the study structure and purpose, requested to read and sign an informed consent form, and complete a brief questionnaire on their sociodemographic and disease characteristics. The discussion during the focus groups was led by an experienced moderator with a background in life and social sciences. All sessions were audiotaped with permission of the participants, and after completion transcribed verbatim.

A guide was constructed to discuss the following: symptoms that patients experienced during hypoglycemia events and their frequency/severity (for this a visual measurement aid was provided); the actions they undertook when experiencing such symptoms; the impact of hypoglycemia on their work, daily activities, physical activities, family and social life; fear of hypoglycemia; and depression and/or other psychological effects/symptoms they experienced. Additionally, patients were asked about their experience in communication with physicians, and which source of information on disease management they used. Patients were encouraged to add anything they considered important after each topic and at the end of the focus groups.

After the focus group discussion, patients were asked to complete one generic (Questionnaire on State of Health EQ-5D-3 L) and one disease specific (Russian-version of 'Questionnaire on Low Blood Sugar Level in Adults' developed by the University of the Virginia in 1998) form assessing HRQoL, that had been used in previous studies. ${ }^{7,9}$ The main objective of using these forms was to evaluate their acceptability and validity among Russian-speaking 
patient populations in Ukraine, to capture any missing data for patients who might have been less eager to participate in conversations, and as a comparison to the results received orally.

\section{Data analysis}

Descriptive statistics was used to characterize the sample group in terms of clinical and socio-demographic characteristics. Qualitative information from the focus group discussions was evaluated. A content analysis was used for aspects identified by more than three patients in all focus groups. The transcripts were analyzed by two researchers independently. Categories for data analysis were selected in accordance with the written focus group protocol as follows:

1. Symptoms and management of hypoglycemia;

2. Hypoglycemia as a limitation;

3. Psychological impact of hypoglycemia.

We grouped similar events and incidents into subcategories, selected in accordance with the participants' replies under similar categories, for easier results presentation. ${ }^{10,14}$

\section{Results}

Eighteen men and 15 women with the defined profile were contacted, from which 12 men and 14 women agreed to participate in the focus groups. Table 1 shows the demographic and clinical characteristics of the sample as

Table I Demographic and clinical characteristics

\begin{tabular}{|c|c|c|c|}
\hline Characteristic & $\begin{array}{l}\text { Men } \\
N=12\end{array}$ & $\begin{array}{l}\text { Women } \\
N=14\end{array}$ & $\begin{array}{l}\text { Total } \\
N=26\end{array}$ \\
\hline Mean age (SD) & $\begin{array}{l}47.33 \\
(6.77)\end{array}$ & $\begin{array}{l}57.71 \\
(5.54)\end{array}$ & $\begin{array}{l}52.92 \\
(8.00)\end{array}$ \\
\hline $\begin{array}{l}\text { History of diabetes mellitus } \\
\text { type } 2<2 \text { years, (\%) }\end{array}$ & $2(17)$ & I (8) & $3(12)$ \\
\hline $\begin{array}{l}\text { History of diabetes mellitus } \\
\text { type } 2>5 \text { years, }(\%)\end{array}$ & $6(50)$ & $8(58)$ & $14(54)$ \\
\hline Residence in the city, (\%) & $12(100)$ & $13(93)$ & $25(96)$ \\
\hline Reside with a family, (\%) & $8(67)$ & $13(93)$ & $2 I(8 I)$ \\
\hline $\begin{array}{l}\text { High education degree or } \\
\text { above, (\%) }\end{array}$ & $5(42)$ & $6(43)$ & II (42) \\
\hline Employed, (\%) & $5(42)$ & $7(50)$ & $12(46)$ \\
\hline $\begin{array}{l}\text { Not working because of diabetes } \\
\text { mellitus type } 2,(\%)\end{array}$ & $7(58)$ & $2(14)$ & $9(35)$ \\
\hline $\begin{array}{l}\text { Family income of study participant } \\
\text { below } 375 \text { USD/montha', (\%) }\end{array}$ & $10(83)$ & $12(86)$ & $22(85)$ \\
\hline $\begin{array}{l}\text { Indicated themselves as of } \\
\text { low-income level, (\%) }\end{array}$ & $9(75)$ & $9(64)$ & $18(69)$ \\
\hline $\begin{array}{l}\text { Using oral blood-sugar lowering } \\
\text { medications, (\%) }\end{array}$ & $6(50)$ & $13(93)$ & $19(73)$ \\
\hline Constant insulin users, (\%) & $6(50)$ & $2(14)$ & $8(31)$ \\
\hline
\end{tabular}

Note: accounted exchange rate 1 US dollar/8 Ukrainian hryvnia. Abbreviation: SD, standard deviation. reported by the patients on the written form. The difference between men and women in education and family status is proportional to the general population. ${ }^{22}$ From socioeconomic parameters we can also note a high unemployment rate among type 2 diabetic patients.

The sub-categories retrieved from the groups' discussion are presented in the Table 2.

\section{Category I: symptoms and management of hypoglycemia}

In general, patients participating in the focus groups demonstrated a high level of awareness of their hypoglycemia symptoms, which included: shakiness; hunger; sweating (both men and women); and additionally sleepiness; dizziness; moodiness/irritation; weakness; trouble thinking; and loss of vision among women. For example, one 54-year-old female participant described hypoglycemia as: "[...] when you get or are hungry, an internal tremor begins. And then it intensifies and all your body begins [...] Both your arms, and feet, and weakness, and dizziness." In the written visual form men also indicated weakness and nervous excitation as frequent symptoms.

All participants generally agreed that the most common action taken when hypoglycemia symptoms occur is the consumption of candies, fruits and sweet liquids. Participants also were aware of the consequences of failing to take measures at the onset of hypoglycemia symptoms, most frequently indicating such consequences as loss of consciousness and coma.

A number of participants (five men and seven women) indicated that for a long time they did not know they were experiencing hypoglycemia manifestations: "I just did not pay attention in the beginning" (male, 46); "[...] I simply did not know what was happening to me" (female, 49). Most patients indicated that they independently established the connection between their feeling of sickness and low

Table 2 Categories and sub-categories characterizing daily life for type 2 diabetes mellitus patients experiencing hypoglycemia

Categories as defined in Sub-categories as defined based
the protocol on the input of participants

Symptoms and management of Symptoms of hypoglycemia and Hypoglycemia their frequency Actions in case of event First time hypoglycemia was diagnosed Hypoglycemia as a limitation Hypoglycemia and adaptation Hypoglycemia and social life limitation

Psychological impact of Depression and fear of hypoglycemia hypoglycemia Actions caused by hypoglycemia fear 
blood sugar level after having blood sugar measured at the moment of hypoglycemic condition. Others indicated that their hypoglycemic condition was detected during their hospitalization with a serious clinical condition. Four of six men, who took insulin, indicated that they started to experience hypoglycemia symptoms after initiating insulin therapy. Both men and women indicated that they lacked information on hypoglycemia manifestations at the early stage of developing diabetes mellitus and, therefore, failed to identify it and manage it properly.

\section{Category 2: hypoglycemia as a limitation}

The majority of focus group participants (nine men and five women) made remarks about adapting their rhythm, daily routine, and way of life to cope with periodically-occurring hypoglycemia attacks (Table 3). Adaptation included a decrease in number of trips away, stress prevention, regular food consumption, and urgent preventive actions as soon as she/he began to experience the symptoms of hypoglycemia. All of the participants still experience hypoglycemic

Table 3 Social, physical, and psychological impact of hypoglycemia (data based on focus group session only)

\begin{tabular}{|c|c|c|}
\hline $\begin{array}{l}\text { Events reported during } \\
\text { focus groups }\end{array}$ & $\begin{array}{l}\text { Number of } \\
\text { men reported } \\
N=12\end{array}$ & $\begin{array}{l}\text { Number of } \\
\text { women reported } \\
N=14\end{array}$ \\
\hline \multicolumn{3}{|c|}{ Sub-category: hypoglycemia and social life limitation } \\
\hline Decrease in work productivity & 0 & 3 \\
\hline Decrease in physical activities & 4 & 5 \\
\hline $\begin{array}{l}\text { Decrease in mobility (going } \\
\text { out, or number of long trips) }\end{array}$ & 3 & 5 \\
\hline $\begin{array}{l}\text { Need in small life changes } \\
\text { (like 'eating schedules') }\end{array}$ & 6 & 5 \\
\hline Driving impact (absence) & 5 & $\mathrm{~N} / \mathrm{A}$ \\
\hline \multicolumn{3}{|c|}{ Sub-category: hypoglycemia and adaptation } \\
\hline Some daily routine adaptation & 12 & 13 \\
\hline $\begin{array}{l}\text { Relatives and close friends are } \\
\text { familiar with the problem and } \\
\text { ready to help }\end{array}$ & 7 & 9 \\
\hline Working schedule adaptation & 6 & 5 \\
\hline \multicolumn{3}{|c|}{ Sub-category: depression and fear of hypoglycemia } \\
\hline $\begin{array}{l}\text { Experience periodic fear or } \\
\text { psychological discomfort }\end{array}$ & 12 & 13 \\
\hline $\begin{array}{l}\text { Experience fear to collapse/ } \\
\text { enter coma }\end{array}$ & 10 & 10 \\
\hline Experience depression & 0 & 7 \\
\hline $\begin{array}{l}\text { Change in insulin time } \\
\text { injection (because of fear) }\end{array}$ & 6 & 0 \\
\hline $\begin{array}{l}\text { Additional food consumption } \\
\text { (because of fear) }\end{array}$ & 0 & 3 \\
\hline $\begin{array}{l}\text { Attempts to prevent } \\
\text { hypoglycemia when feel } \\
\text { possible onset }\end{array}$ & 5 & 6 \\
\hline
\end{tabular}

Abbreviation: N/A, not applicable. events periodically due to physical exercise (six women), medications (four men), stress (four men and five women), and disruptions in the regime (seven men and eight women). Two men and four women noted that hypoglycemic events happen to them more frequently during a certain time of the day (usually morning) or during a certain season.

Participants indicated that hypoglycemia has no significant effect on their family life. However, men reported that they try to avoid irritation and family stresses, or prefer to stay alone. Some women indicated a feeling of discomfort in relations with their relatives.

Regarding work productivity, three of the female participants indicated a substantial decrease in productivity because of frequent hypoglycemic events: "It is not just a decrease, I can't do anything" (female, 49). Additionally, women tried to refrain from informing colleagues about the state of their health, being afraid of criticism and possible influence on labor relations. In large groups and social settings, the participants also mainly stay silent about their diabetes because they do not want to burden others with their health problems, or they are ashamed.

Men tried to adapt their working day to the state of their health and seven of them disclosed that they had to leave their jobs because of diabetes mellitus. Employed participants indicated that they needed to change their working day schedules to prevent hypoglycemia attacks.

Regarding physical exercise, participants revealed that they limit physical exertion (four men and five women). Driving a car was not associated with any specific problem (in the male group; there were no female drivers). Almost no difficulties in performing usual daily activities were noticed by participants, but shopping for a long period of time occasionally caused problems for some of them.

Answers provided by participants in the printed EQ-5D-3 L Form (Table 4) showed that they have some difficulties with mobility (walking), feel moderate pain/ discomfort, and experience anxiety/depression.

\section{Category 3: psychological impact of hypoglycemia}

Fear and psychological discomfort were observed as important aggravating factors of hypoglycemia among patients with type 2 diabetes mellitus (Table 3). During the discussion, all except one woman mentioned periodic fear or psychological discomfort because of hypoglycemia. Twenty participants confirmed that they had a fear of collapsing (with diverse reasons given). Men mainly associated the condition of psychological discomfort with anxiety and the inability 
Table 4 Answers provided by participants in printed EQ-5D-3 L form (Russian version)

\begin{tabular}{|c|c|c|c|}
\hline \multirow[t]{2}{*}{ Indicators of quality of life ${ }^{a}$} & \multicolumn{2}{|l|}{ Sex } & \multirow{2}{*}{$\begin{array}{l}\text { Total } \\
\text { N (\%) }\end{array}$} \\
\hline & $\begin{array}{l}\text { Male } \\
\mathbf{N}(\%)\end{array}$ & $\begin{array}{l}\text { Female } \\
\mathbf{N}(\%)\end{array}$ & \\
\hline \multicolumn{4}{|l|}{ I. Mobility } \\
\hline $\begin{array}{l}\text { I have no problems in walking } \\
\text { about }\end{array}$ & $4(33)$ & $2(14)$ & $6(23)$ \\
\hline $\begin{array}{l}\text { I have some problems in walking } \\
\text { about }\end{array}$ & $8(67)$ & $12(86)$ & $20(77)$ \\
\hline \multicolumn{4}{|l|}{ 2. Self care } \\
\hline I have no problems with self care & $12(100)$ & $9(64)$ & $2 \mathrm{I}(8 \mathrm{I})$ \\
\hline $\begin{array}{l}\text { I have some problems washing or } \\
\text { dressing myself }\end{array}$ & $0(0)$ & $5(36)$ & $5(19)$ \\
\hline \multicolumn{4}{|l|}{ 3. Usual activities } \\
\hline $\begin{array}{l}\text { I have no problems with } \\
\text { performing my usual activities }\end{array}$ & $6(50)$ & $4(29)$ & $10(38)$ \\
\hline $\begin{array}{l}\text { I have some problems with } \\
\text { performing my usual activities }\end{array}$ & $6(50)$ & I0 (7I) & $16(62)$ \\
\hline \multicolumn{4}{|l|}{ 4. Pain/discomfort } \\
\hline I have no pain or discomfort & $2(17)$ & $2(14)$ & $4(15)$ \\
\hline $\begin{array}{l}\text { I have a moderate pain or } \\
\text { discomfort }\end{array}$ & $10(83)$ & $12(86)$ & $22(85)$ \\
\hline \multicolumn{4}{|l|}{ 5. Anxiety/depression } \\
\hline $\begin{array}{l}\text { I am moderately anxious or } \\
\text { depressed }\end{array}$ & $12(100)$ & $14(100)$ & $26(100)$ \\
\hline
\end{tabular}

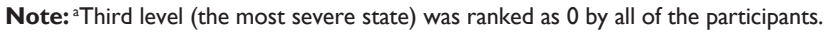

to foresee hypoglycemic events, and fear of hypoglycemia events happening at an inopportune moment or in public. Woman mainly connected the condition of psychological discomfort with the unpredictability of hypoglycemia manifestations, feeling of fear, anxiety, depression, mood swings, irritation and permanent alertness to try and prevent the occurrence of hypoglycemia symptoms. At the same time, unlike men, women were the most afraid of losing consciousness when alone, without anyone nearby who would be able to rescue them: "Psychologically you are afraid each time that something can happen to you. You are going and waiting for something to happen. I am always afraid," (female, 52). Fear of a hypoglycemic event also has a significant impact on participants' behavior: it causes them to shift the time of insulin intake (men), eat an additional meal (women), and limit long trips (both sexes) as presented in Table 3.

Twenty-two of 26 participants (ten men and 12 women) indicated feeling a moderate pain/discomfort on the EQ-5D-3 L. All 26 participants indicated that they feel anxiety and/or depression. According to the HFS Form, for men the most frequent manifestations of anxiety (experienced by nearly half of them) were difficulties maintaining control when it is necessary to bear responsibility for other people, and difficulties performing important tasks because of low blood sugar. For women, the most frequent anxiety manifestations, expressed in the HFS, were the concerns that in case of attack there would be no meal, fruits or juice within their reach.

\section{Hypoglycemia reporting, awareness and sources of information}

Focus group participants revealed that they receive information about diabetes from different sources, but mainly from their endocrinologist. Only seven of 26 people indicated that they also searched for information regarding diabetes in the published lay or scientific literature, and only four participants (all men) indicated that they use internet sources to research information regarding diabetes. During the discussion, six people also shared a positive impact of patients' diabetic educational programs or communication with other patients on information provision. Opinions about whether or not to discuss the problem of hypoglycemia with their physician differed among study participants. Participants (eight men and four women) said that they do not completely trust their physician, and that it is sometimes easier for them to experiment in selecting the most effective methods for hypoglycemia prevention. An interesting difference between the sexes was observed: while the majority of women indicated that their doctor asks about hypoglycemia events during each visit, most of the male participants stated that either the physician did not have time for such questions, or the patient himself was not interested in information provided by the endocrinologist. Several of the male participants described the situation of communication with the doctor as follows: "Theoretically he [the physician] knows everything, but practically he was not in such a situation"; "How can you trust the physician, if the physician does not trust you"; "They [the physicians] do not particularly raise this problem, maybe, because they are not interested in it," (males, 49, 52, and 53 years).

\section{Discussion}

This study aimed to evaluate the symptoms and the management of hypoglycemia, how hypoglycemia episodes might limit patients' daily life, and what is the perceived psychological impact of hypoglycemia among Ukrainian patients. In general, our findings were similar to those reported in other countries.

Regarding symptoms experienced by the patients, autonomic symptoms (shakiness, hunger, sweating) were most frequently reported, by participants in all focus groups. Neuroglycopenic symptoms (weakness, dizziness, and 
irritability) were also frequently reported by the female participants, though we acknowledge that these symptoms can also be related to other health problems. We observed a difference in symptoms-reporting between men and women, with a higher number of symptoms reported among women during the discussion, which is similar to the findings by Marrett et al. ${ }^{7}$

Similar to the findings of other studies, ${ }^{14,23}$ it appears that Ukrainian patients with a long history of the disease (as perceived by patients) are adapting to hypoglycemia. Most of the patients were well informed about the disease symptoms, severity, and the actions required to treat or manage it. Focus group participants not only were able to adjust their nutrition schedule and level of physical activities to manage the disease, but they also adapted their daily activities, working schedules, and private relations to help prevent hypoglycemia and make it more manageable. In the majority of cases, not only family, but also close friends and colleagues of a patient with diabetes mellitus were well informed about his or her state, and were able to provide help in case of emergency; a result observed in previous research. ${ }^{10}$ However, similar to Wu et al's observations, ${ }^{14}$ some participants in this study also preferred to conceal having diabetes at work or in large social settings. Others reported trying to hide not the diabetic state itself but rather the negative health symptoms caused by hypoglycemia, fearing that their health limitations might negatively affect their employment. As in the study by Dickinson and O'Reilly, ${ }^{23}$ we conclude that family, friends, and the work environment can have a significant positive impact on managing type 2 diabetes mellitus complications and on patients' well-being.

We found that "adaptation" to diabetes and associated hypoglycemic states does not always mean absence of negative changes in daily routine: a number of men indicated leaving their job because of diabetes complications; and working women reported a significant decrease in their work productivity because of frequent symptoms such as dizziness and weakness. Because of the need to be constantly alert to the symptoms of hypoglycemia, participants indicated that hypoglycemia events cause disruptions in their daily routines.

The possibility of hypoglycemia events can lead to fear of hypoglycemia and hypoglycemia-related depressions, which are significant factors negatively influencing patients' well-being. Most of the participants indicated verbally that they experienced periodic anxiety and depression because of the possibility of hypoglycemic events, and all patients confirmed this in written form. While some participants (mostly men) are afraid that such events can happen to them in public, others (mostly women) are afraid of hypoglycemic events happening when they are alone and no one is available to provide assistance. The fear of hypoglycemia influences many patients' lives by limiting their social activities, or causing changes in their diabetesmanagement routines (eg, timing of their food intake or insulin injection). Similar findings were observed by other researchers. ${ }^{24}$ These results are in line with the findings from large-scale studies on the impact of hypoglycemia on quality of life. Based on a survey of 1984 participants, Marrett et $\mathrm{al}^{7}$ concluded that patients who experience severe or frequent hypoglycemic episodes report lower general health and greater fear of hypoglycemia compared with patients without a history of hypoglycemia. Hypoglycemia symptom severity was also positively associated with fear of hypoglycemia and lower HRQoL in another study, conducted in the Asia-Pacific region by Sheu et al. ${ }^{9}$ A number of studies in Western countries (UK, France, Sweden, and Germany) have explored hypoglycemia and the impact of its symptoms on both fear of hypoglycemia and HRQoL in patients with type 2 diabetes mellitus, and have reported similar results. ${ }^{1,3-6,25,26}$ Taking into account both results from previous studies, and our study, we can expect that in patients with type 2 diabetes in Ukraine, there should be a similar impact of hypoglycemia on HRQoL, despite possible socio-economic differences between the countries (allowing for some disparities such as sexual gaps in automobile usage and other such habits).

Regarding information provision on disease management, we found that endocrinologists are the most common source of information for type 2 diabetes patients in Ukraine. Primary care practitioners are not typically consulted by patients, and internet resources are also rarely used. These results differ from practice in European countries or the USA, where general practitioners or nurses play important roles in informational support,,$^{8,15-17}$ and the level of internet users among patients with type 2 diabetes reaches approximately $50 \%{ }^{27}$

Despite the fact that in Ukraine, patients are consulted by specialists (endocrinologists) and not by primary care physicians, as in some other countries, ${ }^{8,15-17}$ our results showed that some patients do not rely on their physician and are hesitant to talk to physicians about hypoglycemia, which is a common tendency of diabetic patients also reported in other studies. ${ }^{14,28}$ This might result in the under-reporting of hypoglycemia by type 2 diabetes mellitus patients in Ukraine. 
Under-reporting of hypoglycemia was also shown in the study on 392 participants treated with combinations of oral anti-hyperglycemic agents. ${ }^{1}$

Based on the retrospective experience of focus group participants, we also suppose that newly diagnosed patients with type 2 diabetes mellitus can experience difficulties in managing their condition. Being unaware of hypoglycemic symptoms, newly diagnosed patients might not associate their poor health state with complications of diabetes mellitus, but rather with some other reasons, such as menopause (among women), cardiovascular diseases, and so forth. This leads to impaired awareness that can significantly decrease proper hypoglycemia management and perceived quality of life. ${ }^{11,29}$ We suggest that hypoglycemia awareness programs are important in the early stage of type 2 diabetes mellitus.

The shared experience by the focus group participants suggests that Ukrainian patients experience negative feelings about their state and dissatisfaction in their communications with their physician, and this is similar to the findings from other studies..$^{7-10,30}$ We consider that provision of disease management by primary care practitioners (family doctor or qualified nurse) can improve the level of informational support for Ukrainian patients, because of an increase in duration and frequency of consultations.

\section{Limitations and design considerations \\ Focus groups participants}

The participants were invited to take part in the focus groups by their physician. Despite the fact that the study was conducted by independent researchers at an independent clinical location, the selection of participants might potentially bias the patients' intentions of participating in the research.

All except one of the participants were residents of the largest city in Ukraine. It is possible that the difference between city and village populations (income and education level) could affect reported outcomes. We suspect that village residents with type 2 diabetes mellitus who experience hypoglycemia symptoms might be less knowledgeable about the symptoms and their management, and they might be less likely to report them to their treating physician.

The unemployment rate among focus group participants is significantly higher than the average unemployment rate $(14 \%)$, especially among men. Taking into account lower participation rate among men, we conclude that employment state has an impact on tendency among men to participate in the study. The majority of participants also indicated their family income level to be lower than average in Ukraine. Although it was not our research question, it might be possible that patients with type 2 diabetes in Ukraine experience higher economic vulnerability, an issue which can be explored in future work on diabetes mellitus.

\section{Distribution of written forms}

We chose to give participants the HRQoL forms only after the focus group discussion to prevent patients from talking about events they could potentially have rather than their true personal experiences. We did observe certain differences in the responses provided during the discussion and in writing: the EQ-5D-3 L form drew worse health state conclusions on worse health state in comparison to HFS form; the participants tended to report more symptoms and higher disease severity (especially for men) when they answered the written form. It is possible that men were less inclined than women to share information openly in a group setting, out of fear that it would make them appear weak and/or it would lower their esteem in other participants' eyes, a frequent finding in focus group research. ${ }^{19}$ We believe that providing questionnaires in our study has added valuable insight on patients' experience of hypoglycemia. Future research might be designed to include a time break between these two parts if the study is repeated to reduce the impact of the group discussion on privately obtained information.

\section{Participation in the focus group}

We also observed more difficulties in arranging the male focus groups, in terms of involving patients in the study and finding appropriate times and dates for them to gather together for discussion. Although no reasons were provided, a previous hypoglycemia focus group study contained significantly more female participants than male (14 versus 4 , respectively), perhaps for similar reasons. ${ }^{10}$

It is worth noting that a history of at least one episode of hypoglycemia about which a participant had informed his/ her physician was a criterion for participation in our focus groups. This means that the level of awareness of our focus group participants might be higher than that of an ordinary diabetes patient with similar symptoms.

\section{Conclusion}

The qualitative assessment of hypoglycemia's impact on the lives of patients with type 2 diabetes mellitus using a focus group methodology demonstrated general similarity between 
Ukrainian patients and patients in the other countries. We found serious negative effects of hypoglycemia on psychological and emotional states of participants, as well as limitation of patients' lives because of both the hypoglycemia symptoms themselves and the fear of experiencing them. In contrast to the findings from the other countries, Ukrainian patients rely on endocrinologists as a major informational source, and almost none use electronic informational resources on diabetes management. Though many of the participants were not satisfied with their patient-doctor communications, we conclude that information provision is especially important at the early development of the disease, when patients lack information on hypoglycemia manifestations and can fail to identify and manage the disease properly.

\section{Acknowledgments}

We thank the participants of the focus groups for sharing their personal experience. We also thank Larry Radican and Shengsheng Yu for help with the discussion guide development, and Carter Mandrik for help in manuscript editing.

\section{Disclosure}

This study was financed by MSD Outcome Research. Olena Mandrik is an employee of MSD Ukraine, and Olena Doroshenko and Boris Mankovsky received honoraria for participation in this research. The authors declare no other potential conflicts of interest with respect to the research, authorship, and/or publication of this article.

\section{References}

1. Stargard T, Gonder-Frederick L, Krobot KJ, Alexander CM. Fear of hypoglycaemia: defining a minimum clinically important difference in patients with type 2 diabetes. Health Qual Life Outcomes. Epub October 22, 2009.

2. McAulay V, Deary IJ, Ferguson SC, Frier BM. Acute hypoglycemia in humans causes attentional dysfunction while nonverbal intelligence is preserved. Diabetes Care. 2001;24(10):1745-1750.

3. Currie CJ, Morgan CL, Poole CD, Sharplin P, Lammert M, McEwan P. Multivariate models of health-related utility and the fear of hypoglycaemia in people with diabetes. Curr Med Res Opin. 2006;22(8): 1523-1534.

4. Davis TM, Brown SG, Jacobs IG, Bulsara M, Bruce DG, Davis WA. Determinants of severe hypoglycemia complicating type 2 diabetes: the Fremantle diabetes study. J Clin Endocrinol Metab. 2010;95(5): 2240-2247.

5. Fidler C, Elmelund Christensen T, Gillard S. Hypoglycemia: an overview of fear of hypoglycemia, quality-of-life, and impact on costs. JMed Econ. 2011;14(5):646-655.

6. Lundkvist J, Berne C, Bolinder B, Jönsson L. The economic and quality of life impact of hypoglycemia. Eur J Health Econ. 2005;6(3):197-202.

7. Marrett E, Radican L, Davies MJ, Zhang Q. Assessment of severity and frequency of self-reported hypoglycemia on quality of life in patients with type 2 diabetes treated with oral antihyperglycemic agents: a survey study. BMC Res Notes. Epub July 21, 2011.
8. Pera PI. Living with diabetes: quality of care and quality of life. Patient Prefer Adherence. 2011;5(1):65-72.

9. Sheu WH, Ji LN, Nitiyanant W, Baik SH, Yin D, Mavros P, et al. Hypoglycemia is associated with increased worry and lower quality of life among patients with type 2 diabetes treated with oral antihyperglycemic agents in the Asia-Pacific region. Diabetes Res Clin Pract. 2012;96(2):141-148.

10. Sutton L, Chapman-Novakofski K. Hypoglycemia education needs. Qual Health Res. 2011;21(9):1220-1228.

11. Henderson JN, Allen KV, Deary IJ, Frier BM. Hypoglycaemia in insulin-treated type 2 diabetes: frequency, symptoms and impaired awareness. Diabet Med. 2003;20(12):1016-1021.

12. Coyne KS, Margolis MK, Kennedy-Martin T, et al. The impact of diabetic retinopathy: perspectives from patient focus groups. Fam Prac. 2004;21(4):447-453.

13. Alvarez Guisasola F, Tofé Povedano S, Krishnarajah G, Lyu R, Mavros P, Yin D. Hypoglycaemic symptoms, treatment satisfaction, adherence and their associations with glycaemic goal in patients with type 2 diabetes mellitus: findings from the Real-Life Effectiveness and Care Patterns of Diabetes Management (RECAP-DM) Study. Diabetes Obes Metab. 2008;10 Suppl 1:25-32.

14. Wu FL, Juang JH, Yeh MC. The dilemma of diabetic patients living with hypoglycaemia. J Clin Nurs. 2011;20(15-16):2277-2285.

15. Abdulhadi N, Al Shafaee M, Freudenthal S, Ostenson CG, Wahlström R. Patient-provider interaction from the perspectives of type 2 diabetes patients in Muscat, Oman: a qualitative study. BMC Health Serv Res. 2007;9(7):162.

16. Brez S, Rowan M, Malcolm J, et al. Transition from specialist to primary diabetes care: a qualitative study of perspectives of primary care physicians. BMC Fam Pract. Epub June 6, 2009.

17. Meyfroidt S, Aeyels D, Van Audenhove C, et al. How do patients with uncontrolled diabetes in the Brussels-Capital Region seek and use information sources for their diet? Prim Health Care Res Dev. Epub April 30, 2012.

18. Quah JH, Luo N, Ng WY, How CH, Tay EG. Health-related quality of life is associated with diabetic complications, but not with shortterm diabetic control in primary care. Ann Acad Med Singapore. 2011;40(6):276-286.

19. Fern EF. Advanced Focus Group Research. Thousand Oaks, CA: Sage Publications; 2001.

20. Liamputtong P. Focus Group Methodology: Principle and Practice. Thousand Oaks, CA: Sage Publications; 2011.

21. Litosseliti L. Using Focus Groups in Research. Continuum Research Methods Series. London: Continuum International Publishing Group; 2003.

22. State Service of Statistics of Ukraine. Social and Demographical characteristics of Households in Ukraine in 2012 (based on households survey). Ukraine: State Service of Statistics of Ukraine, 2012. Available from: http://www.ukrstat.gov.ua/druk/katalog/kat_u/2012/06_2012/ zb_sd_2012.zip. Accessed November 12, 2012.

23. Dickinson JK, O'Reilly MM. The lived experience of adolescent females with type 1 diabetes. Diabetes Educ. 2004;30(1):99-107.

24. Sutin DG. Diabetes mellitus in older adults: time for an overtreatment quality indicator. J Am Geriatr Soc. 2010;58(11):2244-2245.

25. Redekop WK, Koopmanschap MA, Stolk RP, Rutten GE, Wolffenbuttel BH, Niessen LW. Health-related quality of life and treatment satisfaction in Dutch patients with type 2 diabetes. Diabetes Care. 2002;25(3):458-463.

26. Vexiau P, Mavros P, Krishnarajah G, Lyu R, Yin D. Hypoglycaemia in patients with type 2 diabetes treated with a combination of metformin and sulphonylurea therapy in France. Diabetes Obes Metab. 2008;10 Suppl 1:S16-S24.

27. Cho AH, Arar NH, Edelman DE, Hartwell PH, Oddone EZ, Yancy WS Jr. Do diabetic veterans use the Internet? Self-reported usage, skills, and interest in using My HealtheVet Web portal. Telemed J E Health. 2010;16(5):595-602. 
28. Gonder-Frederick LA, Cox DJ, Ritterband LM. Diabetes and behavioral medicine: the second decade. J Consult Clin Psychol. 2002;70(3): $611-625$

29. Bailey CJ. Hypoglycaemia: a limiting factor. British Journal of Diabetes and Vascular Disease. 2010;10(1):2-4.
30. Hepburn DA, Deary IJ, Freir BM. Classification of symptoms of hypoglycaemia in insulin-treated diabetic patients using factor analysis: relationship to hypoglycaemia unawareness. Diabet Med. 1992;9(1):70-75.

\section{Publish your work in this journal}

The Journal of Multidisciplinary Healthcare is an international, peerreviewed open-access journal that aims to represent and publish research in healthcare areas delivered by practitioners of different disciplines. This includes studies and reviews conducted by multidisciplinary teams as well as research which evaluates the results or conduct of such teams or healthcare processes in general. The journal covers a wide range of areas and welcomes submission from practitioners at all levels, from all over the world. The manuscript management system is completely online and includes a very quick and fair peer-review system. Visit http://www.dovepress.com/testimonials.php to read real quotes from published authors.

Submit your manuscript here: http://www.dovepress.com/journal-of-multidisciplinary-healthcare-journal 